\section{Over-the-counter (OTC) bruxism splints available on the Internet}

\author{
R. W. Wassell, ${ }^{* 1}$ L. Verhees, ${ }^{1}$ K. Lawrence, ${ }^{1}$ S. Davies ${ }^{2}$ and F. Lobbezoo ${ }^{3}$ \\ VERIFIABLE CPD PAPER
}

IN BRIEF
- Raises awareness and categorises the
types of over-the-counter (OTC) bruxism
splints available on the Internet.
- Highlights the potential pitfalls of
patients purchasing an OTC bruxism
splint without consulting a dentist.
- Provides advice on the UK regulation of
these appliances.
- Stresses that dentists should report
suspected adverse events with OTC
splints to the relevant authority.

\begin{abstract}
Background Some individuals may now be bypassing their dentists for treatment of bruxism. Self-diagnosed, selfadjusted and self-monitored consumers can access over-the-counter (OTC) bruxism splints via the Internet. While some may regard this market as benefiting consumers there are potential pitfalls that need to be highlighted. These include unevidenced claims of efficacy. Objective To survey OTC bruxism splints available to individuals in the UK via the Internet, categorise their characteristics, and determine any web-based claims or safety warnings. Materials and methods An Internet search was made of OTC bruxism splints available in the UK. The following information was recorded for each OTC splint: the name of the manufacturer, name of the device, its UK price and any claims and safety warnings made either on a major UK retail website or via other UK web retail outlets. In addition, a note was made of any web-based mention of 'CE marking', indicating compliance with the EC Medical Devices Directive's requirements for safety, quality and performance. Results Safety information is notable for its paucity and is totally lacking on many Internet sites. However, manufacturers are not obliged to display safety information on the Internet, but it must be provided with the product. A search of the MAUDE database showed a number of potentially serious adverse events associated with these splints including choking hazards, tissue damage and occlusal changes. None of the splint designs assure full occlusal coverage. Conclusions As with any partial coverage appliance, if worn for protracted periods there may be a risk of unwanted tooth movement. Dentists should report or assist patients with reporting suspected adverse events with OTC splints to the relevant competent authority. In the UK this is the Medicines and Healthcare Products Regulatory Agency (MHRA).
\end{abstract}

\section{INTRODUCTION}

Bruxism, as recently defined by an international expert group, is 'a repetitive jaw-muscle activity characterised by clenching or grinding of the teeth and/or by bracing or thrusting of the mandible. Bruxism has two distinct circadian manifestations: it can occur during sleep (indicated as sleep bruxism) or during wakefulness (indicated as awake bruxism).' It is a common disorder affecting an estimated $16 \%$ of the adult population for sleep bruxism and 24\% for awake bruxism. ${ }^{2}$ Clearly some subjects will be affected by both types of bruxism.

\footnotetext{
'Department of Restorative Dentistry, The School of Dental Sciences, Framlington Place, Newcastle upon Tyne, NE2 4BW; ${ }^{2}$ TMD Clinic, Dental School, Higher Cambridge Street, Manchester, M15 6FH; ${ }^{3}$ Department of Oral Kinesiology, Academic Centre for Dentistry Amsterdam (ACTA), University of Amsterdam and VU University Amsterdam, MOVE Research Institute Amsterdam, Amsterdam, The Netherlands

${ }^{*}$ Correspondence to: R. W. Wassell

Email robert.wassell@ncl.ac.uk
}

Online article number E24

Refereed Paper - accepted 23 January 2014

DOI: 10.1038/sj.bdj.2014.452

${ }^{\circ}$ British Dental Journal 2014; 216: E24
Bruxism is a persistent but fluctuating problem in many subjects. ${ }^{3}$

While patients can be counselled to help control awake bruxism other methods are needed to control sleep bruxism, particularly when patients develop associated symptoms of jaw or tooth pain, or where they wish to protect teeth or restorations from damaging occlusal forces. It should be emphasised that while the occlusion is at the receiving end of parafunctional activity it is not the cause of it and sleep bruxism is now regarded as a centrally-mediated, sleep-related disorder. ${ }^{4}$ Consequently, it is inappropriate for dentists to recommend invasive treatments to correct occlusal discrepancies as a primary treatment for bruxism (although in order to improve predictability, it is sensible to avoid incorporating occlusal discrepancies in bruxists who require restorative treatment). Nowadays, non-invasive treatments for bruxism are recommended including occlusal splints of various designs supplemented by advice and occasional pharmacological intervention. Despite the lack of substantial scientific evidence supporting any particular splint design as being effective in reducing bruxism many authorities still recommend full coverage stabilisation splints ${ }^{2}$ to spread occlusal contact optimally $^{5}$ and avoid unwanted occlusal changes..$^{5-7}$ The full coverage stabilisation splint, which is also used extensively for the management of some temporomandibular disorders (TMD), is generally regarded as a safe option. ${ }^{8,9}$ Clinically when adjusted properly it works well for many sleep bruxism patients, but it is not a panacea with the response of patients being variable and unpredictable. ${ }^{10}$ While the stabilisation splint does not efficiently treat bruxism in all patients it is often used over long periods to protect the teeth in patients who continue to brux. ${ }^{10}$ Contraindications to this type of splint are not absolute but include sleep apnoea ${ }^{11,12}$ and unstable disc displacements with reduction. ${ }^{13}$

Another type of full coverage splint is the soft splint - a popular choice with many dentists, being quick and easy to fit. Clinically some patients are happy with this appliance, but others find their bruxism aggravated more than in patients wearing stabilisation splints. ${ }^{14}$ Whether this effect results from the resilient nature of the material or the splint's unprescribed occlusion is not known. 
There are also dentists who advocate partial coverage splints such as the NTITSS splint, which in some patients may successfully reduce clenching ${ }^{6}$ or may be helpful as a short-term treatment for acute TMD. However, to avoid unwanted occlusal changes, dentists fitting such appliances are advised to fit them only in those patients who are likely to be compliant with follow-up appointments. ${ }^{6,9}$

Nowadays, the Internet has added a new dimension to dentistry. Not only are individuals increasingly aware and informed of health related conditions they can now obtain over-the-counter (OTC) appliances online as a possible alternative in an attempt to manage their bruxism (also for snoring and sleep apnoea) without the need for a dental or medical consultation. In the context of this paper an individual buying an oral device without advice or supervision of an appropriate dental healthcare professional is termed a 'consumer'. A 'patient' is defined as an individual under treatment by a dental healthcare professional. An individual may be both a patient and a consumer if they omit to tell their dentist that they are using an OTC splint.

OTC splints originated in the US but are increasingly available in the UK and other parts of Europe. Companies are distributing online and via other commercial outlets (for example, pharmacies and supermarkets). There is also a trend for some dentists to sell OTC appliances directly to patients. OTC splints come in a variety of designs allowing them to be fitted to different jaw sizes.

The aim of this paper is to survey OTC bruxism splints available to individuals in the UK via the Internet, categorise their characteristics, and determine any webbased claims or safety warnings. Further, an online search was made for possible complications including unwanted occlusal change. Finally, advice is given regarding the UK regulation of these appliances and the need for appropriate reporting.

\section{MATERIALS AND METHOD}

An Internet search was made (10 March 2013) of OTC bruxism splints available in the UK and determine if these were also available in the US. The search engines and phrases used are shown in Table 1. With each search phrase ten search engine pages were searched for OTC bruxism splints. Sites were identified as UK sales points if prices quoted were in pounds sterling or US sites if in dollars. For each OTC splint the name of the splint was used as a search term and pursued for ten search engine pages to determine the respective retail outlets.
The following information was recorded for each OTC splint: the name of the manufacturer, name of the device, its UK price and any claims and safety warnings made either on a major UK retail website or via other UK web retail outlets. In addition, a note was made of any web-based mention of 'CE marking', indicating compliance with the EC Medical Devices Directive's requirements for safety, quality and performance. In the context of performance this does not need to be supported by clinical trial data to show efficacy and safety if a manufacturer or supplier submits a medical device as low-risk.

The manufacturer's claims posted on the UK websites were tabulated and two of the authors (RWW and LV) categorised them into a number of common themes. A similar approach was made for any caution notice or safety advice existing on the relevant UK website.

A classification of OTC bruxism splints was devised by grouping the splints according to similarity in design. The classification considered the broad type of design and whether it potentially provided full coverage of all the teeth in one arch or was specifically partial coverage. The classification also took into account splint adjustability. In order to check appropriate classification a splint from each manufacturer was ordered on line for physical inspection. In all, 22 splints were ordered, including three OTC impression systems.

The Internet search was repeated (04/07/13) using the same protocol to corroborate the findings of the March survey. This July survey identified any further splints being marketed in the UK as well as any additional or changed claims and safety warnings. A note was made of any splints no longer being sold since the first survey and any identified checked online (15/07/13). The web pages were all copied via the "print screen' command and saved as Word files allowing the table contents to be crosschecked by a second investigator.

\section{Online search for associated adverse events}

To determine if OTC bruxism splints had been associated with any adverse events a generic search in the US Food and Drug Administration's (FDA) 'Manufacturer and User Facility Device Experience Database' (MAUDE) $)^{15}$ was carried out. The following strategy was used: Go to simple search $\rightarrow$ search term: bruxism; date report received by FDA: ALL YEARS (that is, between 1992 and 2013). The results were hand searched to select OTC bruxism splints from other products. Subsequent search terms were used
Table 1 Search engines and phrases used to locate OTC splints available the UK and determine if also available in the US

Search engines used

www.google.co.uk

www.google.com

Amazon.co.uk

Amazon.com

Search phrases used

'Bruxism protection'

'Bruxism guard'

'Bruxism mouth guard'

'Bruxism appliance'

'Night guard'

'Occlusal splint'

'Occlusal bite guard'

'Bite plate'

to generate additional hits. These included all the generic terms derived from the product names in Table 2 ('grinding guard' 'grinding gard', 'night guard', 'nightguard', 'nightguard', 'bite guard', 'dental splint', 'dental guard' and 'bruxo') and the product names themselves. Reports of reactions to splint cleaning products were not included, neither were in-surgery devices customised by the dentist. By carrying out the search on the same computer all previously viewed database entries were highlighted allowing irrelevant products and those previously selected to be excluded. Each set of searches was saved as a Word file. Any duplicate entries were excluded and multiple reports for the same incident were collated into a single entry. For each entry the reporter (manufacturer, consumer or dentist), incident summary and date were identified. Common themes to describe the various incidents were agreed between three of the authors (RWW, FL and SD).

\section{RESULTS}

The splints available from UK websites and their characteristics are summarised in Table 2 with sub-tables explaining the codes used to summarise the manufacturers' claims and the Internet-based safety warnings. Table 2 shows splints available in both the March and July surveys with the boxes shaded light grey identifying splints introduced after the March survey. Prices, manufacturer's claims and Internet-based safety warnings relate to the July survey. Where any significant change in claims or safety warnings had taken place between the two surveys these are mentioned within the text below.

In the March survey a total of 22 different splints supplied by 13 manufacturers/ suppliers were identified with all but one of the manufacturers selling their products via a single major UK retail website. One of the splints is not shown in the table as it was no longer available in the July survey. This 
Table 2 Master table showing four categories of splint design available in the UK with prices, coded claims and safety warnings. Survey data

\section{for July 2013}

Split design

Adjustability

Unretentive

gutter

('Full coverage')

One size fits all

Manufacturer/

supplier

Device name

TotalGard

Trimmed with

\begin{tabular}{l|l} 
& scissors
\end{tabular}

Bite Pads on

posterior teeth

('Partial

coverage')

Boil E⿱tete

Boil \&t bite

('Full coverage')

(1)

One size fits all

Self-adjustable

pads;

with 4 settings

One size fits all

Self-adjustable

pads;

with 5 settings

One size fits all

Trimmed with

scissors

\begin{tabular}{|l|l|}
\hline 2PLUS2 & Pair of Night Guards Mouth Guards for Bruxism \\
\hline BruxPerformance ** & BruxoGard \\
\hline
\end{tabular}

Price $\quad$ Manufacturer

\begin{tabular}{|l|l}
\cline { 2 - 2 } & Physiogard Nightguard Stressgard II Biteguard \\
\hline OnceAll & OnceAll Dual Layers Dental Teeth Boxing Mouth \\
\hline
\end{tabular}

Guard Stop Night Teeth Grinding

SleepRight

Dental Guard Dura- Comfort

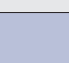

$€ 30.00$

(Den

Dentek

\begin{tabular}{|l|l|l}
\hline \multirow{2}{*}{ Dentek } & Dental Guard Slim-Comfort & $£ 29.9$ \\
\hline 2PLUS2 & Comfort Fit Dental Guard & \\
\hline BruxPerformance $^{* *}$ & Pair of Night Guards Mouth Guards for Bruxism & $£ 29.9$ \\
\hline & BruxoGard & $£ 24.3$
\end{tabular}

\begin{tabular}{|c|c|c|c|c|}
\hline & Maximum Protection Dental Guard & $€ 29.98$ & $D, F, G$ & $\begin{array}{l}2^{*}, 66^{*}, 10^{*}, \\
12^{*}, 13^{*}, \\
16^{*}, 17^{*}, 27^{*}, \\
28^{*}, 29^{*}, 30^{*}, \\
31^{*}, 32^{*}, 33^{*}, \\
34^{*}, 35^{*}, 36^{*}, \\
37^{*}, 38^{*}\end{array}$ \\
\hline Dr Brux & $\begin{array}{l}\text { Dr Brux Mouthpiece (generally unavailable except } \\
\text { via Italian supplier trading in pound sterling) }\end{array}$ & $€ 61.00$ & $\mathrm{C}, \mathrm{H}$ & - \\
\hline Icebrite & $\begin{array}{l}\text { Pair of Night Guard Mouth Guards to Prevent Teeth } \\
\text { Grinding }\end{array}$ & $€ 3.95$ & $A, C, D$ & - \\
\hline $\begin{array}{l}\text { Mammoth } \\
\text { Supplements }\end{array}$ & Grinding Teeth Guard (Bruxism); Berry Flavour & $£ 5.49$ & D & - \\
\hline \multirow{2}{*}{$\begin{array}{l}\text { Sleep Solutions } \\
\text { (Myofunctional } \\
\text { Research Co) }\end{array}$} & Sleep Solutions Bruxogard Soft Mouth Guard & $£ 24.43$ & $B^{*}, D, E$ & - \\
\hline & Sleep Solutions Bruxogard Hard Mouth Guard & $€ 35.27$ & $\mathrm{~B}^{*}$ & 8 \\
\hline 2PLUS2 & $\begin{array}{l}\text { Thermoforming Mouth Trays for Teeth Grinding/ } \\
\text { Bleaching/ Whitening }\end{array}$ & $€ 1.25$ & - & 1 \\
\hline AllThingsLovelyJubbly & $\begin{array}{l}\text { Stop Snoring Anti Snoring Device Sleep and Mouth } \\
\text { Piece Guard Teeth Grinding Cure }\end{array}$ & $£ 10.99$ & C & $6,15,22,23$ \\
\hline Archtek & $\begin{array}{l}\text { Grinding Guard - Relieves Symptoms Associated } \\
\text { with Teeth Grinding }\end{array}$ & $£ 10.70$ & $A^{*}, B^{*}, D$ & - \\
\hline Doctors & $\begin{array}{l}\text { Med Tech Products Doctors Nightguard Advanced } \\
\text { Comfort }\end{array}$ & $€ 23.65$ & $C^{*}, D^{*}$ & - \\
\hline MAKS & $\begin{array}{l}\text { 2pcs Replacement Thermoforming Mouth Trays/ } \\
\text { Guards for Teeth Whitening/ Bleaching or Teeth } \\
\text { Grinding }\end{array}$ & €1.99 & - & - \\
\hline \multirow[t]{2}{*}{ Mammoth XT } & $\begin{array}{l}\text { Bruxism Grinding Teeth Mouth Guard- Sleep Gum } \\
\text { Shield / Night NightGuard / Boil n Bite - Spearmint }\end{array}$ & $£ 5.99$ & $A, D$ & - \\
\hline & $\begin{array}{l}\text { Mammoth XT Pair of Teeth Grinding Mouth Night } \\
\text { Guard - Bruxism }\end{array}$ & $£ 19.99$ & $A, D$ & - \\
\hline Smile 4 You & $\begin{array}{l}\text { Replacement Thermoforming Mouth Trays/ Guards } \\
\text { for Teeth Whitening/ Bleaching or Teeth Grinding }\end{array}$ & $€ 2.48$ & - & 9 \\
\hline Start Here & $\begin{array}{l}\text { 4x Replacement Thermoforming Mouth Trays/ } \\
\text { Guards for Teeth Whitening/ Bleaching or Teeth } \\
\text { Grinding }\end{array}$ & $£ 0.01$ & - & - \\
\hline Top Choice & $\begin{array}{l}\text { Replacement Thermoforming Mouth Trays/ Guards } \\
\text { for Whitening/ Bleaching or Teeth Grinding }\end{array}$ & $€ 2.35$ & - & 9 \\
\hline
\end{tabular}


Table 2 Master table showing four categories of splint design available in the UK with prices, coded claims and safety warnings. Survey data for July 2013

\section{Continued from page 3}

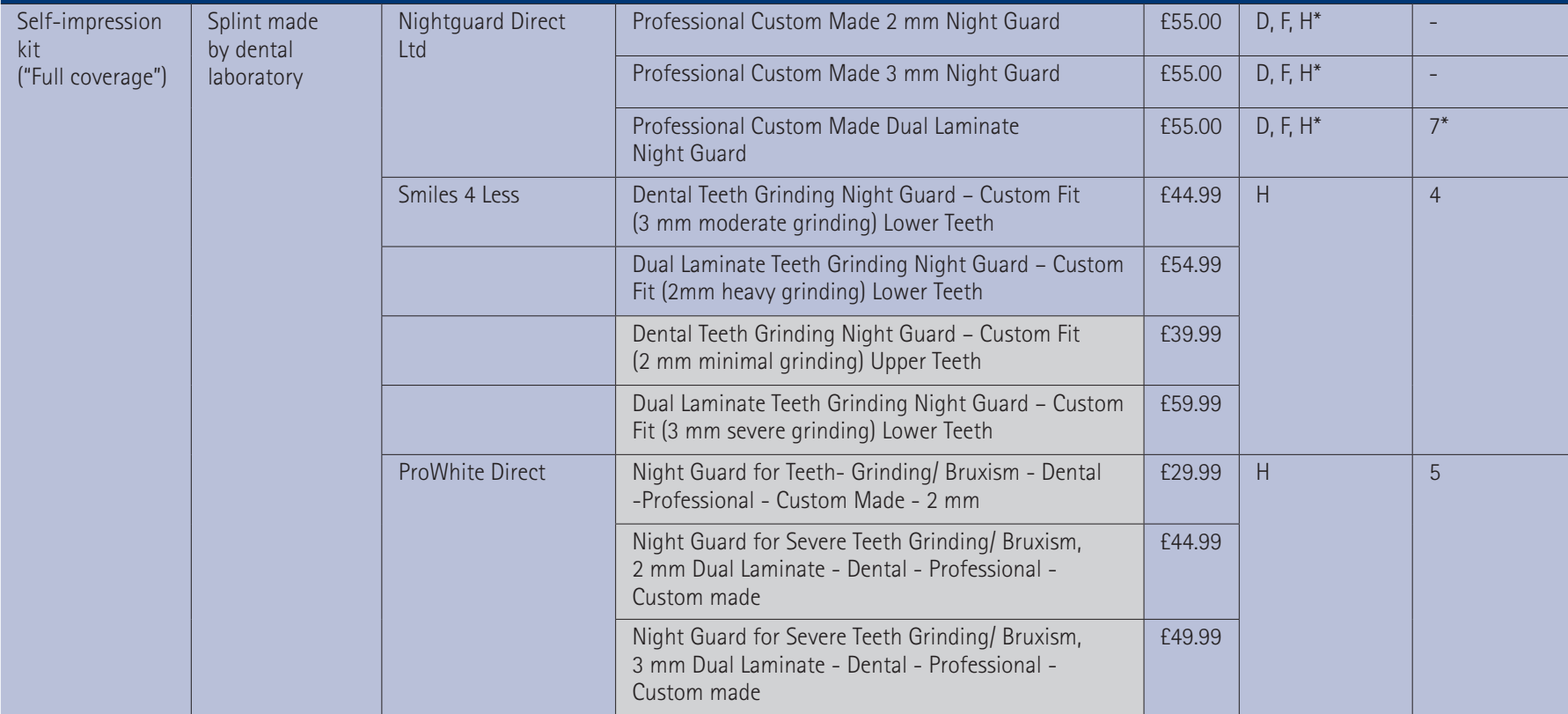

was a laboratory made splint made from a self-recorded impression. Eleven of the 22 splints available on UK websites were also available on US websites. In the July survey the number of splints available in the UK had risen to 37 and the number of manufacturers/ suppliers to 23. Twelve of the 37 splints were also available on US websites.

Four generic designs were identified, three of them having the potential for full coverage while one design was intentionally partial coverage:

1. The unretentive gutter - a U shaped plastic device placed between the dental arches and adjusted by the individual with scissors

2. Bite pads on posterior teeth - the pads are connected bilaterally to buccal flanges in the molar/premolar regions. The buccal flanges are in turn connected by a thin plastic strap that sits in the lower buccal sulcus. The individual can adjust the pads using a number of different settings depending on lower arch size. As with the 'unretentive gutter' there is no retention provided from the teeth with the interocclusal portion balanced between the upper and lower arches

3. Boil and bite - Fitted in the same way as a thermoplastic sports mouth guard and adjusted by the individual with scissors

4. Self-impression kit - The individual is sent an impression kit (tray and putty) and returns the self-made impression to a commercial laboratory. A soft, vacuum formed splint is custom made by the laboratory and returned to the individual.

As only one manufacturer mentioned CE certification online this information was not tabulated. The need for CE certification to accompany the product when delivered to the end-user will be raised in the discussion.

OTC bruxism splints ranged in price from $£ 0.01$ to £61.00, but postage and packing could add as much as $£ 17.00$ to the price, particularly if the appliance was sent via a UK retail website but from a supplier outside the UK. Some appliances are sold in packs of two or four.

The types of manufacturers' claims for their products can be seen in the sub-table (i) of Table 2. Some of the claims were available on the main UK retail website while others were only available on the manufacture's/ supplier's website. The most common claim (16 splints) was 'Protects teeth/restorations from grinding /clenching/bruxism'. Other commonly made claims (four to six splints) suggested that splints 'Protects the TMJ' or 'Cures/treats/reduces/helps/prevents bruxism' or reduces unspecified symptoms. Five products carried a claim of 'Headaches/ facial pain/jaw pain reduction' while one claimed to improve sleep/reduce sleep disruption. Six products claimed to be similar to professionally made splints but less expensive. Some manufactures/suppliers made claims about splints in general but not necessarily about the product on sale.

There was a variety of Internet-based safety warnings as seen in sub-table (ii) of
Table 2. Again, some of this information was only available on the manufacture's/ supplier's website. One splint was supported by a comprehensive list of 19 safety items, but 14 splints carried no safety information on their websites. Detailed safety notices comprising 15-16 items were provided for five splints in the March survey, but in the July survey these had all been removed by one manufacturer and reduced to two items by another. Strangely, one manufacturer in the March survey advised their Grinding Teeth Guard; Berry Flavour 'Not to be used as a nightguard to prevent against bruxism', however, in the July survey that solitary warning had been removed. There was an inconsistency in the minimum age with three manufactures each recommending 10, 14 and 16 years respectively. A further three manufacturers set the minimum age at 18 . No minimum age was mentioned by the other 17 manufacturers.

Only two manufacturers provided a guide to how long each day the splint should be worn. One recommended no more than 12 hours in each 24 hour period for 3 months before consulting a dentist. The other endorsed wear of the splint throughout the day or the night to help relieve tooth grinding symptoms.

\section{Online search for associated adverse events}

The results of the MAUDE adverse events database are shown in Table 3. In total 20 reports were identified relating to those 


\begin{tabular}{|c|c|}
\hline Code & Manufacturer claims \\
\hline - & No claims \\
\hline A & Headaches/facial pain/jaw pain reduction \\
\hline B & Unspecified symptom reduction \\
\hline C & Cures/treats/reduces/helps/prevents bruxism \\
\hline D & Protects teeth/restorations from grinding/clenching/bruxism \\
\hline E & Protects TMJ from grinding/clenching/bruxism \\
\hline $\mathrm{F}$ & Claims similar but less expensive than professionally made splint \\
\hline G & Improves sleep/reduces sleep disruption \\
\hline H & Generic claims about splints not specific to product on sale \\
\hline J & Other (eg most durable, years of success, re-establishes space between upper and lower teeth) \\
\hline
\end{tabular}

Table 3 Search results from the FDA's MAUDE database for adverse events associated with OTC bruxism splints

\begin{tabular}{|c|c|c|c|c|}
\hline Search term & $\begin{array}{l}\text { OTC bruxism } \\
\text { splints }\end{array}$ & Total hits & Previous hits & $\begin{array}{l}\text { Irrelevant } \\
\text { products }\end{array}$ \\
\hline Bruxism & $12^{*}$ & 118 & 0 & 106 \\
\hline Grinding guard & 4 & 14 & 4 & 6 \\
\hline Nightguard & 4 & 18 & 8 & 6 \\
\hline Specific products ${ }^{* *}$ & 1 & 16 & 8 & 7 \\
\hline Total number of incidents & 20 & & & \\
\hline
\end{tabular}

found for the OTC bruxism splints. Only the generic terms 'bruxism', 'grinding guard' and 'nightguard' generated relevant entries; one further entry was discovered by sequentially entering all the product names. Summaries of the adverse events are shown in Table 4 while the themes describing the types of event are shown in Table 5 . Eleven adverse events were reported by manufacturers and nine by consumers. No reports were made by dentists. All of the reports except three were made between 2008 and 2013.

\section{DISCUSSION}

This Internet survey clearly indicates the variety of OTC bruxism splints currently available to individuals in the UK. From a customer's perspective this market may appear attractive giving freedom of choice and being less expensive than a splint fitted and followed up by a dentist. It also saves time waiting for a dental appointment. The manufacturers and suppliers of OTC bruxism splints can also claim directly (through online or printed information) or indirectly (through promotion and advertising) to have raised awareness of bruxism to consumers and to the dental profession. Indeed, there is some potentially helpful information available to consumers about awake bruxism (for example, SleepRight provides information for consumers based on a three step selfhelp philosophy of awareness, accountability and behaviour modification). However, this rapidly emerging market in the UK throws up a number of important issues that the dental profession should be aware of.

Currently, UK dentists may be unaware that consumers can bypass some of their professional services by way of the Internet. Indeed, they may well have patients using OTC appliances who fail to volunteer this information. As with the prolonged wear of any intra-oral appliance individuals may be at greater risk of developing dental problems (for example, unwanted occlusal changes, mucosal trauma and dental disease where the oral hygiene is inadequate).

OTC bruxism splints have been available in the US for almost 20 years and are a thriving business. Indicative figures from one manufacturer suggest several hundred thousand splints sold annually in the US and increasing sales in Europe. In our March survey over half of the companies selling OTC splints in the UK originate from the US indicating an intention to grow the market this side of the Atlantic. However, our July survey showed only one further US company entering the UK market, which had increased in 4 months by $68 \%$ (in terms of number of different splints). Some of the companies most recently entering the UK market appear to
Table 2(ii) Codings for manufacturers' claims in main table

\begin{tabular}{|c|c|}
\hline Code & Caution notice on the Internet \\
\hline- & None \\
\hline 1 & $\begin{array}{l}\text { Not to be worn to prevent against } \\
\text { bruxism }\end{array}$ \\
\hline 2 & Not to be worn as a sports guard \\
\hline 3 & Not for persons $<10$ years old \\
\hline 4 & Not for persons $<14$ years old \\
\hline 5 & Not for persons $<16$ years old \\
\hline 6 & Not for persons $<18$ years old \\
\hline 7 & $\begin{array}{l}\text { Only for use when recommended by } \\
\text { a dentist }\end{array}$ \\
\hline 8 & For night time use only \\
\hline \multirow[t]{2}{*}{9} & For mild grinders only \\
\hline & Do not use: \\
\hline 10 & $\begin{array}{l}\text { For more than } 3 \text { months without } \\
\text { consulting your dentist }\end{array}$ \\
\hline 11 & $\begin{array}{l}\text { For more than } 6 \text { months without } \\
\text { consulting your dentist }\end{array}$ \\
\hline 12 & $\begin{array}{l}\text { If your dentist has told you that you } \\
\text { have TMJ pain or clicking }\end{array}$ \\
\hline 13 & $\begin{array}{l}\text { If you have tooth pain from grinding } \\
\text { or any other tooth or jaw pain }\end{array}$ \\
\hline 14 & If you have jaw problems \\
\hline 15 & If you have tooth or gum problems \\
\hline 16 & $\begin{array}{l}\text { With dentures, braces or other dental } \\
\text { appliances eg implants }\end{array}$ \\
\hline 17 & $\begin{array}{l}\text { With loose teeth, loose fillings or loose } \\
\text { crowns }\end{array}$ \\
\hline 18 & A bridge \\
\hline 19 & Advanced periodontal disease \\
\hline 20 & Several missing teeth \\
\hline 21 & For $>12$ hours in a 24 hour period \\
\hline 22 & If you suffer from sleep apnoea \\
\hline \multirow[t]{2}{*}{23} & If you suffer from epilepsy \\
\hline & Consult a dentist before use if you: \\
\hline 24 & Have tooth or gum problems \\
\hline 25 & Wear a denture or brace \\
\hline 26 & Are under 14 years of age \\
\hline 27 & $\begin{array}{l}\text { Have major health problems or serious } \\
\text { breathing problems }\end{array}$ \\
\hline 28 & $\begin{array}{l}\text { Oral sores, bleeding gums or any gum } \\
\text { disease }\end{array}$ \\
\hline 29 & Cavities with no fillings \\
\hline 30 & Difficulty chewing \\
\hline 31 & Pain of the jaw, teeth or face \\
\hline \multirow[t]{2}{*}{32} & Two or more missing teeth \\
\hline & Stop using the splint and ask a dentist if: \\
\hline 33 & $\begin{array}{l}\text { Soreness, bleeding gums, teeth loosen } \\
\text { or reaction occurs in mouth }\end{array}$ \\
\hline 34 & $\begin{array}{l}\text { Pain develops e.g. jaw, teeth or ear pain } \\
\text { or headache }\end{array}$ \\
\hline 35 & $\begin{array}{l}\text { The splint causes gagging, discomfort } \\
\text { or falls out of the mouth easily }\end{array}$ \\
\hline 36 & A change in the bite is noticed \\
\hline 37 & Neck stiffness or joint clicking develops \\
\hline 38 & $\begin{array}{l}\text { The same symptoms persist after one } \\
\text { month of use }\end{array}$ \\
\hline
\end{tabular}



Table 4 MAUDE adverse event summaries $(n=20$ ) from all specified search terms showing
who made the report (consumer $C_{1}$ dentist $D$ or manufacturer $M$ ) coding the type of problem according to Table 5. (MAUDE database updated 30.11.2013)

\begin{tabular}{|c|c|c|}
\hline $\begin{array}{l}\text { Reporter } \\
\text { C, D, M }\end{array}$ & Incident summary & $\begin{array}{l}\text { Incident } \\
\text { code }\end{array}$ \\
\hline C & $\begin{array}{l}\text { Scalding of consumer's hand and face caused by microwave heated water } \\
\text { contained in a drinking glass. On immersing the splint the water "exploded" } \\
\text { boiling up steam and superheated water over consumer's skin. }\end{array}$ & 1 \\
\hline M & $\begin{array}{l}\text { Uncomfortable splint which consumer considered was causing severe gum } \\
\text { irritation and loss of a filling. }\end{array}$ & 2,6 \\
\hline M & $\begin{array}{l}\text { Gingival recession around lower molars requiring surgical intervention - possibly } \\
\text { caused by splint. Claim supported by manufacturer's insurance in view of } \\
\text { dentist's contention that appliance may have been causative. }\end{array}$ & 3 \\
\hline M & $\begin{array}{l}\text { Open sore developed in gums after wearing splint for } 3 \text { days. Plastic material } \\
\text { (possibly from splint) impacted into gum requiring surgical removal resulting in } \\
\text { bone and gingival tissue loss. Device available for evaluation but packaging not } \\
\text { kept so lot number unknown. }\end{array}$ & 3 \\
\hline C & $\begin{array}{l}\text { Painful blisters inside mouth after wearing splint for one night. Splint no longer } \\
\text { worn and blisters resolved }\end{array}$ & 4 \\
\hline M & $\begin{array}{l}\text { Tooth pain after one night of wearing splint. Patient reports dentist diagnosed a } \\
\text { cracked lower molar on each side of her mouth. }\end{array}$ & 5 \\
\hline M & $\begin{array}{l}\text { Splint broke apart and tooth damage. Consumer considered damage caused } \\
\text { by the way her teeth grind on splint. Manufacture requested product from } \\
\text { consumer to investigate, but no response. }\end{array}$ & 7,5 \\
\hline C & $\begin{array}{l}\text { Splint broke during sleep. Consumer (occupation risk manager) perceived a } \\
\text { choking hazard. }\end{array}$ & 7 \\
\hline M & $\begin{array}{l}\text { Consumer woke with pieces of the splint stuck in her throat after only two nights } \\
\text { of wearing the device. Concern over possibility of aspiration. }\end{array}$ & 7 \\
\hline M & $\begin{array}{l}\text { Appliance partly swallowed during sleep. Wife woke husband because of his } \\
\text { choking noises and retrieved appliance using her fingers. Emergency room } \\
\text { treatment required, possibly due to pharyngeal injury during removal. }\end{array}$ & 8 \\
\hline M & $\begin{array}{l}\text { Appliance partly swallowed during sleep causing gagging. Patient able to } \\
\text { self-retrieve. }\end{array}$ & 8 \\
\hline M & $\begin{array}{l}\text { Appliance partly swallowed during sleep causing gagging. Patient able to } \\
\text { self-retrieve. }\end{array}$ & 8 \\
\hline M & $\begin{array}{l}\text { Appliance completely swallowed during sleep two weeks prior to contacting } \\
\text { manufacturer to demand refund. }\end{array}$ & 8 \\
\hline C & $\begin{array}{l}\text { 'Lock jaw tmj' after wearing splint for only } 7 \text { hours. Told by dentist condition } \\
\text { could last for years. Patient aggrieved as splint bought only to treat bruxism. No } \\
\text { mention of TMD history. }\end{array}$ & 9 \\
\hline M & $\begin{array}{l}\text { Progressive occlusal change after one year of wearing splint every night. } \\
\text { Dentist advised patient to discontinue splint wear but teeth continued to move } \\
\text { over following year resulting in "teeth not closing", development of a } 5 \mathrm{~mm} \\
\text { anterior open-bite, chewing difficulties and development of a lisp. Dentist } \\
\text { supporting patient in upgrading case to serious. Remedial orthodontic treatment } \\
\text { recommended. }\end{array}$ & 10 \\
\hline C & $\begin{array}{l}\text { Bite has changed and jaw pain after using splint for one month. Splint no longer } \\
\text { used but symptoms persist. }\end{array}$ & 10 \\
\hline C & $\begin{array}{l}\text { Gave consumer 'bad gas' during } 5 \text { months of wear. Event abated after use } \\
\text { stopped. }\end{array}$ & 11 \\
\hline C & $\begin{array}{l}\text { "Brown stuff" in mouth followed by general malaise for } 3 \text { days. Consumer } \\
\text { suspects contamination or chemical leaching from splint. }\end{array}$ & 11 \\
\hline C & $\begin{array}{l}\text { Consumer concerned product needed a safety seal packaging as it appeared that } \\
\text { other products on the shelf had been opened and handled. }\end{array}$ & 12 \\
\hline C & $\begin{array}{l}\text { 'Dried blood' noticed on splint being sold at drug store suggesting it had already } \\
\text { been used. }\end{array}$ & 12 \\
\hline
\end{tabular}

be UK based, but it is difficult to determine from where many of them are trading and whether any are offering the same product, but under different names. Companies include some dental laboratories. These laboratories sell an OTC impression kit but supply a splint customised to fit an individual customer. By the time of the July survey one of these laboratories was no longer advertising. We will consider the UK regulation implications of both mass produced and custom made devices later in the discussion. However, the practice of laboratories supplying an OTC impression kit and a custom made appliance currently falls in a regulatory grey area. The Medicines and Healthcare products Regulatory Agency (MHRA) considers it to be a matter for the professional bodies, which in the UK is the

\begin{tabular}{l|l|}
\hline \multicolumn{2}{|l|}{ Table 5 MAUDE adverse event categories } \\
and codings based on reports in Table 4 \\
\hline Type of adverse event & Code \\
\hline Scalding & 1 \\
\hline Gingival irritation and discomfort & 2 \\
\hline Gingival damage or recession & 3 \\
\hline Mucosal reaction & 4 \\
\hline Cracked, damaged or painful tooth & 5 \\
\hline Lost or damaged restoration & 6 \\
\hline Splint broken in use (+/- choking) & 7 \\
\hline $\begin{array}{l}\text { Splint swallowed/part swallowed during } \\
\text { sleep (+/- choking) }\end{array}$ & 8 \\
\hline $\begin{array}{l}\text { TMD (diagnosis part-confirmed by } \\
\text { dentist) }\end{array}$ & 9 \\
\hline Occlusal change & 10 \\
\hline Systemic reaction & 11 \\
\hline Product contamination & 12 \\
\hline
\end{tabular}

General Dental Council (GDC) who have been made aware of the situation.

The proposed classification system provides a useful tool to differentiate between the growing numbers of OTC bruxism splints available. An interesting trend observed with the July survey is the marketing of several multi-purpose devices to be used not only for bruxism but also as anti-snoring appliances (one product) or bleach trays (five products). Readers should be aware that while 'boil and bite' OTC bruxism splints closely resemble sports mouth guards in appearance the former are classified by the MHRA as medical devices while the latter are not. Consequently, sports mouth guards that are used intermittently for short periods are not governed by the same regulatory framework. However, if an OTC sports mouth guard were marketed for the purpose of managing bruxism it would be regulated in the UK by the MHRA.

There are a number of significant pitfalls with consumers buying OTC splints and bypassing their dentist. Not least, it relies on the consumer self-diagnosing their condition, which may be more complex than simply one of tooth grinding and clenching. For example, a consumer with facial pain may buy an OTC splint in the hope that it will solve the problem, but the pain may have little or nothing to do with bruxism and the opportunity for a professional diagnosis may be delayed or lost. Alternatively, a consumer may be diagnosed by their dentist, but buy an OTC splint because they find the one provided by their dentist too expensive or too onerous in terms of follow-up requirements. While one manufacturer 
states in their Internet safety warning that consumers with jaw or tooth pain should ask their dentist before OTC splint use, there are 22 manufacturers in the July survey who make no such recommendation. Consumers may be further confused when they read on one site that an OTC splint may be used to treat jaw pain but other sites say that jaw pain is a contraindication to use. It would be interesting to know how many consumers with jaw or tooth pain do consult their dentist after browsing an OTC website or, having bought the splint, after reading the accompanying instructions.

Consumers browsing with the intention of buying an OTC bruxism splint online may find it difficult to gauge how safe these products are: most web sites (including the major UK retail website and those of the suppliers/manufacturers) either have no safety warnings or only mention a lower age limit. Even then they fail to agree whether this should be aged 10,14, 16 or 18 years. Where safety information is given it is unknown to what extent consumers comprehend or comply with it. Moreover, manufacturers and suppliers may decide for whatever reason to remove safety notices from websites so that information regarding potentially deleterious effects of appliances is no longer available to potential customers. This action was observed with two manufacturers when we repeated our Internet survey in July, but we understand that manufacturers and resellers are not legally obliged to give full information online. However, they are obliged to do so when the product is delivered to the end user. As well as providing information, the product needs to be marked with a 'CE' mark indicating compliance with the Medical Devices Directive, considered later in the regulatory section of the article.

It is worth emphasising that the major UK retail website, where all but one of the products are sold, issues a legal disclaimer in relation to the web-based information for all their healthcare products. The disclaimer advises consumers not to rely on this information for self-diagnosis or self-treatment. In addition, consumers are advised to read the information and safety warnings that come with products. If the consumer purchases from a UK-based seller, they are covered by the UK Distance Selling Regulations. ${ }^{16}$ This provides protection for consumers when they enter into a contract with an online supplier. The consumer has 7 working days from the day after the receipt of the goods to examine the goods and determine if they are suitable (some manufacturers offer 14 days, but if no information on returns is provided the consumer has up to 3 months and 7 days). If they are dissatisfied for any reason they can return the goods for a full refund. Similar provisions apply to sellers based in the EU. Assuming the product arrives with the necessary cautions and instructions the consumer has in theory sufficient time to consult the manufacturer or their dentist if they require further clarification. In practice how many take the trouble to do so is unclear and may be worthy of further research.

Consumers will assume that the materials used to make these splints are safe. Clearly, some splints have the potential to leach substances intra-orally as illustrated by the berry and mint flavours of two products. To what extent other substances (for example, phthalates) leach out is unknown. Under current regulatory arrangements (see below) manufacturers are not obliged to submit clinical trial data for their products showing both safety and efficacy. Neither are there specific ISO (International Standards Organization) standards for the materials these products are made from as there are for polymeric materials used in dentistry (for example, denture and orthodontic bases). ${ }^{17}$ However we understand ISO is becoming aware of the need to consider this further.

With regard to efficacy Table 2 shows a wide range of claims being made by manufacturers for their products, but it is difficult to know on what basis they are being made as there is no published research regarding OTC splints. Claims stating that a splint will cure bruxism, reduce headaches and facial pain or improve sleep quality need to be viewed with particular caution. While some claims allude to splints in general, consumers may not unreasonably assume that these apply to the splint on sale without realising that it has no published trial results. In the UK the Advertising Standards Authority is responsible for enforcing codes relating to medical device advertising. These codes are written and maintained by the Committee of Advertising Practice. ${ }^{18}$ So far we are unaware of any manufacturer's claims made for OTC bruxism splints being scrutinised by the ASA.

\section{Online search for associated adverse events}

The search of the MAUDE database provided a qualitative analysis of the type of problem generically associated with OTC bruxism splints. Although derived from the American experience this information should be helpful to dentists and consumers in the UK. We made no attempt to identify specific manufacturers and splints, although 'boil and bite' splints can be recognised from the scalding incident. No reports were made by dentists, but two consumers had been advised and supported by dentists where extensive remedial treatment was required. Some reported events are of concern, particularly the choking hazard caused by individuals swallowing or inhaling parts of a broken appliance or indeed occasions where the splint is swallowed whole. Patients may wrongly associate local and systemic symptoms with the wear of an OTC splint. Nevertheless, gross gingival trauma, development of trismus ('TMJ lockjaw') and changes to the occlusion are events that clearly should not be ignored. We will return to the issue of occlusal changes in the following section.

We acknowledge that this type of search will have shortcomings particularly in respect of under reporting recognised by the FDA. ${ }^{15}$ Furthermore, the reports are not evidence of proof of causation. Neither is there sufficient of them to show superiority of one product over another or to identify features of a product predisposing to particular adverse events. Reports of contaminated or potentially contaminated packaging relate to sales from shops rather than Internet trade.

OTC bruxism splints have been available for almost 20 years but MAUDE consumer reports have only really started in the past 5 years. Until recently reporting has not been easy for consumers. The FDA now recognises that the reporting form is 'too technical' and has collaborated with consumer groups to produce a more user friendly version. ${ }^{19}$ Nevertheless, consumers and dentists need to know that regulatory reporting is expected of them; if not, under-reporting may well continue.

Despite the reports on the MAUDE database there are no published case reports. This may indicate that problems rarely occur with OTC bruxism splints. However, there are case reports and trial data showing occasional problems with professionally fitted appliances for example, stabilisation splints, ${ }^{13}$ soft splints $^{7}$ and partial coverage appliances. ${ }^{6}$ The recurring theme with these reports is the possibility of unwanted tooth movement and occlusal change - particularly with partial coverage splints.

\section{Unwanted tooth movement and partial coverage splints}

All of the OTC splints surveyed in this study had the potential to be partial coverage, either by design or as a result of simply not fitting the full arch. This misfit between splint and arch may occur following adjustment of a 'one size fits all splint' by an individual using scissors. Alternatively, individuals recording their own impressions 
before splint construction may not include all of the teeth. They are after all not trained in recording impressions, and taking a good impression on yourself would represent a challenge, even for a dental professional.

The literature reports that partial coverage appliances have the potential to cause tooth movement via dento-alveolar intrusion of the teeth covered by the appliance and extrusion or over-eruption of those not covered. ${ }^{20,21}$ The resulting tooth movements can either be planned, as part of some orthodontic or restorative treatment, ${ }^{21,22}$ or unwanted..$^{6,7,23}$ Indeed, recommendations have been made only to prescribe partial coverage splints where dentists are sure of patient compliance with follow-up. ${ }^{6,9}$

The potential for tooth movement will increase with prolonged wear of the partial coverage splint. For example, Dahl and Krogstad $^{24}$ showed that 6-14 months of partial coverage splint wear on the anterior teeth caused a combination of incisor intrusion and molar over-eruption. The incisors intruded by a mean of $1 \mathrm{~mm}$ while the molars had over-erupted by $1.5 \mathrm{~mm}$. It is generally accepted that orthodontic tooth intrusion is not easily achieved but incisors have the potential to intrude more than molars (mean values of $1.5 \mathrm{~mm}$ compared with $1 \mathrm{~mm}) .{ }^{25,26}$ Other studies have shown that following extraction unopposed teeth can erupt to varying extents in different patients ranging from $0.5 \mathrm{~mm}$ to $5.4 \mathrm{~mm} .{ }^{27}$

The Gelb appliance is a partial coverage splint, which is a custom made appliance for TMD, enjoying a period of popularity during the 1980s and 1990s. This appliance only covers the posterior teeth leaving the anterior teeth separated. We know from clinical observations and from study results that in some patients prolonged wear of the Gelb appliance results in posterior open bite, particularly when worn fulltime. ${ }^{28}$ Brown et al. ${ }^{28}$ reported a study of 64 patients wearing Gelb appliances for between 6 months and 4.8 years. A subgroup of 16 patients had complete radiographic records (lateral cephalographs) with the splint removed before and after treatment. All 16 of them had developed posterior open bites following treatment. Various significant tooth intrusions and extrusions were reported for the 64 patients using measurements recorded from the radiographs. However, the mandibular molars did not show significant intrusion. Such measurements may have been subject to inherent methodological limitations. ${ }^{12}$ Hence, we are uncertain whether the 16 posterior open bites resulted either from changes in tooth position or changes in mandibular posture or both. To what extent these posterior open bites resolved with time was not reported. Clearly, the full-time wear of a Gelb appliance incorporating indentations which hold the jaw forwards is an extreme form of splint therapy. We must emphasise that while some OTC bruxism splints superficially resemble the Gelb appliance, they do not have indentations and the instructions recommend sleep use and not full-time wear. Consequently, any hazard of producing unwanted tooth movement should be much less, if used only for sleep and for limited periods.

In the UK dentists routinely create interocclusal space of 1-2 $\mathrm{mm}$ for restorative purposes using the Dahl approach. ${ }^{22}$ This tooth movement is often achieved in only 3-4 months. Hence, many UK and other European dentists increasingly recognise the potential for unwanted occlusal change with prolonged wear of partial coverage appliances. This clinical experience in combination with the above studies illustrates the potential for unwanted tooth movement with any partial coverage splint, particularly in susceptible individuals when worn for protracted periods.

If a consumer buys an OTC bruxism splint without the knowledge and supervision of a dentist, then the potential for unwanted occlusal change is increased as the consumer may not be looking out for it. Furthermore, the insidious nature of occlusal change may allow a considerable change to occur before the consumer becomes aware of a problem. It is assumed that many patients will buy OTC bruxism splints for overnight wear to control the effects of sleep related bruxism. In this respect splint wear occurring during the hours of sleep may be considered 'short-term' and an assumption, backed by some bodies of expert opinion, made of low risk. However, patients with both awake and sleep related bruxism may decide to wear their splints for longer periods, particularly if the instructions that come with the splint are unclear about the potential hazards of unwanted tooth movement and the need to limit the amount of splint wear. The low level of evidence based on expert opinion also needs to be born in mind. ${ }^{29}$ Clearly, it would be helpful if the question of what constitutes a safe period of wear of a partial coverage splint could be answered with a properly conducted clinical trial. Sufficient numbers of patients would of course be needed to ensure the trial included those who were susceptible to unwanted tooth movement. The ethical considerations of undertaking such a trial would of course need careful consideration.

Given the potential for unwanted tooth movement it is surprising there are only two MAUDE database entries and no published case reports of this occurring with OTC bruxism splints. Perhaps one of the reasons is not being $100 \%$ sure about proof of causation. Individuals buying OTC splints will rarely have comprehensive records for comparison. In the case study below the only evidence that the teeth had moved was based on retrospective information: the patient history, the occlusal analysis and the two dental panoramic tomographic (DPT) radiographs. Other factors such as the unerupted wisdom teeth, differences in X-ray machines, TMD symptoms and masseteric hypertrophy complicate the presentation in this case. Nevertheless, where dentists have a strong suspicion of causation they have an ethical obligation to assist their patients in reporting safety issues to the relevant regulatory agency. Moreover, if the dentist has prescribed the OTC splint he or she has a professional obligation to do so - much in the same way as UK doctors do with the 'Yellow card' system used for reporting suspected side effects with drugs. This obligation, previously implicit in GDC's Standards for dental professionals, ${ }^{30}$ has become explicit in the new Standards published September 2013. ${ }^{31}$ Indeed, both the General Medical Council ${ }^{32}$ and the Royal College of Surgeons ${ }^{33}$ are now also keen to emphasise the responsibility of health care professionals in reporting problems with medical devices.

Case study: occlusal change suspected to be associated with an OTC splint

A 22-year-old male patient was referred to Newcastle Dental Hospital with a 6 year history of bruxism and more recently disturbance in his occlusion. The patient explained that his teeth met prematurely at the back of his mouth and was increasingly aware of sliding his lower jaw and teeth to improve the number of teeth meeting. In addition, he had a dull pain over the insertion of left masseter and left masseteric hypertrophy.

Previous treatment by his dentist had included the provision of lower soft splints to address his bruxism while his left sided masseteric hypertrophy was managed by the maxillofacial surgeons with botox injections. He repeatedly perforated the lower soft splints around the canine regions, so in January 2011, unbeknown to his dentist, he purchased an OTC bruxism splint over the Internet. He continued to wear the selfprescribed appliance each night for 8 months, even replacing it when it became too worn. However, towards the end of this period he began to notice an increasing problem with his bite when he removed appliance.

On examination the patient had a large 
slide between the retruded contact position and intercuspal position. The slide had a $3 \mathrm{~mm}$ lateral component to the left. The retruded contact was between teeth 27 and 37. Clinically both of these teeth appeared over-erupted, as did teeth 17 and 47 . When the appliance was placed in the patient's mouth it extended only to the distal aspects of 46 and 36 leaving all the second molars uncovered. By contrast, the soft splint supplied by the patient's dentist covered all the lower teeth. A DPT revealed a distinct step between the first and second molars (Fig. 1). A previous DPT, which predated the use of the appliance, is shown in Figure 2.

Diagnoses were made of occlusal disruption associated with overeruption of the second molars and prolonged wear of an OTC splint leaving these teeth uncovered, sleep related bruxism, left sided masseteric hypertrophy and mild left sided myofascial pain. At this point the patient was instructed to stop wearing the OTC splint immediately and use only the soft splint provided by his dentist. He was also counselled on the importance of biting together on his second molars while swallowing but otherwise to avoid clenching his teeth. In addition, remedial jaw exercises were prescribed to be carried out two to three times a day for his TMD symptoms. Following occlusal analysis with mounted study casts, arrangements were made for the unerupted 18 and 28 to be extracted and after initial settling of the occlusion he was successfully fitted with a stabilisation splint. Treatment extended over eight appointments. The occlusion re-interdigitated successfully without occlusal adjustment and his TMD symptoms were well controlled. We recommended the patient continue to wear his stabilisation splint while the sleep bruxism was active. The masseteric hypertrophy will continue to be reviewed by the maxillofacial surgeons and the occlusion will continue to be reviewed by the restorative dentists.

\section{European regulation and reporting problems with OTC bruxism splints}

UK Dentists will be aware of the MHRA in relation to prescribing custom made appliances. The MHRA is also the competent authority in the UK in relation to OTC bruxism splints. Other countries in the EU have their own competent authorities, which have similar arrangements to the MHRA.

Manufacturers self-certify the risk level of their products and, on the basis that bruxism splints should just be worn overnight, the EC Medical Devices Directive agrees with them being categorised as Class 1 medical device or 'low risk'. As the market for medical devices, including OTC bruxism splints, is international the evidence presented by manufacturers may include certification or approval from other authorities (for example, the FDA in the US).

Responsible manufacturers need to comply with the requirements operating in the country where they wish to sell their products. Within the UK and most other European countries manufacturers of OTC bruxism splints must deliver appropriate literature (indications, instructions and cautions) to the end user and mark their OTC products with a 'CE mark'. The CE mark indicates compliance with the EC Medical Devices Directive's requirements for safety, quality and performance. For Class I appliances manufacturers have to self-declare compliance by submitting a dossier but, as mentioned previously, do not need to submit trial data for their product showing efficacy and safety. In addition, manufacturers must register with the competent authority where they or their authorised European representative is based. In the UK the MHRA also has a market surveillance and enforcement role. Under these arrangements manufacturers are expected to monitor any reports received from healthcare professionals, patients or consumers involving their products. There are generic guidelines that apply to all classes of medical device which inform manufacturers when to notify the MHRA regarding significant events. ${ }^{34}$ A significant event would be one that 'led, or might have led, to death or to a serious deterioration in state of health'. With such a high threshold it would be unlikely that the MHRA would receive many reports from manufacturers of OTC bruxism splints. However, we can see from Table 4 there are several associated hazards (for example, scalding, choking, tissue damage, occlusal changes and onset of TMD significantly impacting on patient's quality of life) that the MHRA would expect manufacturers to report.

Recognising the need to identify any emerging safety issues the MHRA encourages healthcare professionals, patients and consumers to report issues with medical devices using their online reporting tool. In this way they can update their adverse incident database. The MHRA advise that some apparently minor incidents may have greater significance when aggregated with other similar reports. So, it is better to report a suspected adverse incident than ignore it.

A summary of advice on reporting to the MHRA and at the same time to manufacturers can be found below.

If a patient has had a problem requiring specialist referral we recommend the specialist assist with the task of reporting.

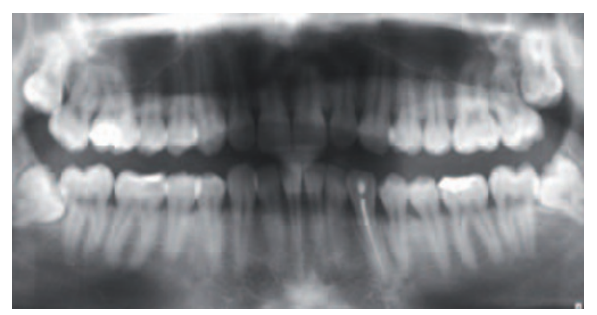

Fig. 1 DPT recorded on presentation, highlighting a distinct step between the distal aspects of all four first molars and the adjacent mesial aspects of the second molars

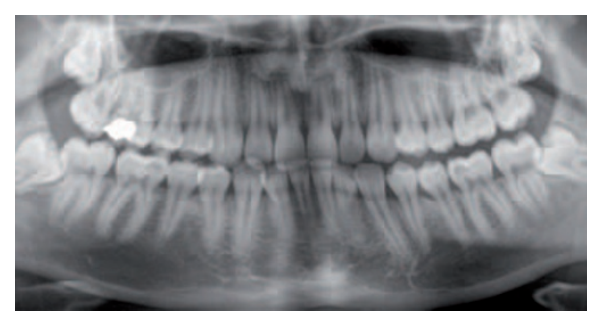

Fig. 2 DPT recorded 3.5 years before presentation - no step in the occlusal plane is evident

Whoever makes the report should bear in mind that this may be a suspected adverse reaction. In other words absolute proof of causation is not expected by the MHRA.

On receipt of a report the MHRA will also correspond with the manufacturer and if necessary investigate and resolve any potential breaches of the regulations that implement the EC Medical Directive into UK law. This may involve checking that the technical documents the manufacturer is required to hold demonstrate conformity with the requirements of the Directive. The MHRA therefore need to know about products being sold without a CE marking.

For readers in other European countries who come across problems with OTC splints details of the relevant competent authorities may be found at: http://ec.europa.eu/health/ medical-devices/files/list-of-contact-pointswithin-the-national_en.pdf

\section{Advice on reporting issues with OTC bruxism splints}

Where a dentist, a patient or a consumer experiences problems associated with an OTC bruxism splint:

- Report the problem both to the MHRA and to the manufacturer

- Dental care professionals should assist their patients with reporting

- There are separate forms for dental care professionals and for patients/ consumers to report issues: http:// www.mhra.gov.uk/Safetyinformation/ Reportingsafetyproblems/Devices/index. htm

- The OTC splint should be kept by the dentist or the consumer. The MHRA may require the splint to be examined 
and tested. If so they will request for the splint to be sent to the manufacturer who will report directly to the MHRA.

\section{Advice on monitoring partial coverage splints}

If a dentist is aware that a patient is wearing a partial coverage splint (either custom made or OTC) it is crucial that he or she monitors for unwanted occlusal change. The simplest way of doing this is to record an occlusal examination before a patient embarks on treatment. In this way any changes in shim stock contacts ${ }^{35}$ can be detected at future appointments. Another excellent method of recording an archive of occlusal contacts is to use the occlusal sketch technique. ${ }^{36,37}$ In addition, impressions can be made and casts poured as a three-dimensional baseline record so that any subsequent changes can be detected visually. We advise prospective monitoring as it allows changes to be picked up before they become irreversible and both difficult and expensive to treat. Where early changes are detected patients can be advised either to discontinue use or try a custom made full-coverage design.

Unless a dentist prescribes an OTC splint, or is aware that their patient has started to wear a self-prescribed splint, it is hard to see how baseline records could have been taken of the occlusal condition before splint treatment started. Therefore, if problems occur a retrospective assessment will be needed. For this purpose we advise study casts, photographs and radiographs where clinically justifiable. The photographs should highlight changes that appear associated with the splint wear. It is also worth recording an occlusal examination or occlusal sketch as mentioned previously. If previous records exist these should of course be retrieved for comparison.

\section{CONCLUSION}

This paper considers the possibility that individuals may be bypassing their dentists by buying OTC bruxism splints on the Internet. Dentists need to keep this market in mind when reviewing patients to check if they are using such appliances, particularly if there are unexplained occlusal changes or other problems.

Where problems occur it is good practice to inform the appropriate competent authority, which in the UK is the MHRA.

Bruxism is often a long-term problem and because tooth movements are not considered desirable in its management, the use of custom made full coverage splints is still recommended unless there are specific contra-indications. With any type of bruxism appliance the importance of regular review is critical.

We are grateful to the MHRA for their advice regarding the $E U$ regulatory aspects of this article.

1. Lobbezoo F, Ahlberg J, Glaros A G et al. Bruxism defined and graded: an international consensus. J Oral Rehabil 2013; 40: 2-4

2. Lobbezoo F, Ahlberg D, Manfredini D, Winocur E. Review article: are bruxism and the bite causally related? J Oral Rehabil 2012; 39: 489-501.

3. Carlsson G E, Egermark I, Magnusson T. Predictors of bruxism, other oral parafunctions, and tooth wear over a 20-year follow-up period. J Orofac Pain 2003; 17: 50-57.

4. Lobbezoo F, van der Zaag J, van Selms M K, Hamburger $\mathrm{H}$ L, Naeije M. Principles for the management of bruxism. J Oral Rehabil 2008; 35: 509-523.

5. Moufti M A Lilico J T, Wassell R W. How to make a well-fitting stabilization splint. Dent Update 2007; 34: 398-400, 402-404, 407-408.

6. Stapelmann H, Turp J C. The NTI-tss device for the therapy of bruxism, temporomandibular disorders, and headache- where do we stand? A qualitative systematic review of the literature. BMC Oral Health 2008; 8: 1-23.

7. Chate R A, Falconer D T. Dental appliances with inadequate occlusal coverage: a case report. Br Dent J 2011; 210: 109-110.

8. Mobilio N, Catapano S. European Academy of Craniomandibular Disorders - patient information. European Academy of Craniomandibular Disorders, 2013. Online information available at http://www. eacmd.org/patient.php (accessed March 2014).

9. Fricton J, Look J O, Wright E et al. Systematic review and meta-analysis of randomized controlled trials evaluating intraoral orthopedic appliances for temporomandibular disorders. J Orofac Pain 2010; 24: 237-254.

10. van der Zaag J, Lobbezoo F, Wicks D J, Visscher C M Hamburger H L, Naeije M. Controlled assessment of the efficacy of occlusal stabilization splints on sleep bruxism. J Orofac Pain 2005; 19: 151-158.

11. Nikolopoulou M, Naeije M, Aarab G, Hamburger H L Visscher C M, Lobbezoo F. The effect of raising the bite without mandibular protrusion on obstructive sleep apnoea. J Oral Rehabil 2011; 38: 643-647.

12. Nikolopoulou M, Ahlberg J, Visscher C M, Hamburger $H$ L, Naeije M, Lobbezoo F. Effects of occlusal stabilization splints on obstructive sleep apnea: a randomized controlled trial. J Orofac Pain 2013; 27: 199-205.

13. Magdaleno F, Ginestal E. Side effects of stabilization occlusal splints: a report of three cases and literature review. Cranio 2010; 28: 128-135.

14. Okeson J P. The effects of hard and soft occlusal splints on nocturnal bruxism. J Am Dent Assoc 1987; 114: 788-791

15. US Food and Drug Administration. MAUDEManufacturer and User Facility Device Experience. [Online information available at http://www. accessdata.fda.gov/scripts/cdrh/cfdocs/cfmaude/ textsearch.cfm (accessed March 2014).

16. Office of Fair Trading. A short guide for business on distance selling. London: OFT, 2008. Online guide available at http://www.oft.gov.uk/shared_oft/ business_leaflets/general/oft913.pdf (accessed March 2014).

17. International Organization for Standardization Dentistry - base polymers - part 2: orthodontic base polymers. ISO/FDIS 20795-2:2013. ISO, 2013. Online information available at http://www.iso.org/ iso/iso_catalogue/catalogue_tc/catalogue_detail. htm?csnumber $=62279$ (accessed March 2014)

18. Committees of Advertising Practice. Medical devices - advertising advice. CAP, 2013. Online advice available at http://www. cap.org.uk/Advice-Training-on-the-rules/ Advice-Online-Database/Medical-devices.aspx (accessed March 2014).

19. US Food and Drug Administration. WANTED: consumers to report problems. Online article available at http://www.fda.gov/ForConsumers/ ConsumerUpdates/ucm354560.htm (accessed March 2014)

20. Dahl B L, Krogstad O. The effect of a partial bite-raising splint on the inclination of upper and lower front teeth. Acta Odontol Scand 1983; 41: 311-314.

21. Saha S, Summerwill A J. Reviewing the concept of Dahl. Dent Update 2004; 31: 442-444, 446-447.

22. Poyser N J, Porter R W, Briggs P F, Chana HS, Kelleher M G. The Dahl concept: past, present and future. Br Dent J 2005; 198: 669-676.

23. Dincer $M$, Meral 0 , Tumer $N$. The investigation of occlusal contacts during the retention period. Angle Orthod 2003; 73: 640-646.

24. Dahl B L, Krogstad O. The effect of a partial bite raising splint on the occlusal face height. An X-ray cephalometric study in human adults. Acta Odontol Scand 1982; 40: 17-24

25. Ng J, Major P W, Flores-Mir C. True molar intrusion attained during orthodontic treatment: a systematic review. Am J Orthod Dentofacial Orthop 2006: 130: 709-714.

26. Ng J, Major P W, Heo G, Flores-Mir C. True incisor intrusion attained during orthodontic treatment: a systematic review and meta-analysis. Am J Orthod Dentofacial Orthop 2005; 128: 212-219.

27. Craddock $H L$, Youngson C C. A study of the incidence of overeruption and occlusal interferences in unopposed posterior teeth. Br Dent J 2004; 196: 341-348.

28. Brown D T, Gaudet E L Jr, Phillips C. Changes in vertical tooth position and face height related to long term anterior repositioning splint therapy. Cranio 1994; 12: 19-22.

29. Centre for Evidence Based Medicine. Oxford Centre for Evidence-based Medicine- levels of evidence (March 2009). CEBM, 2009. Online information available at http://www.cebm.net/index.aspx?o=1025 (accessed March 2014).

30. General Dental Council. Standards for dental professionals. London: GDC, 2005

31. General Dental Council. Standards for the dental team. London: GDC, 2013.

32. General Medical Council. Good medical practice. Contribute to and comply with systems to protect patients (section 23c). London: GMC, 2013.

33. Lennard $N$, Coutinho $M$, Campbell $D$. The surgeon and medical devices: adverse incident reporting and off label use. Ann R Coll Surg Engl 2013; 95: 309-310.

34. European Commission, DG Health and Consumer (SANCO). Guidelines on a medical devices vigilance system. European Comission, 2013 Online guidelines available at http://ec.europa.eu/health/medicaldevices/files/meddev/2_12_1_ol_en.pdf (accessed March 2014).

35. Steele J G, Nohl FS, Wassell R W. Crowns and other extra-coronal restorations: occlusal considerations and articulator selection. Br Dent J 2002; 192: 377-380, 383-377.

36. Davies S J, Grey R J, Al-Ani M Z, Sloan P, Worthington $\mathrm{H}$. Inter-and intra-operator reliability of the recording of occlusal contacts using 'occlusal sketch' acetate technique. Br Dent J 2002; 193: 397-400.

37. Davies S, Al-Ani Z, Jeremiah H, Winston D, Smith P. Reliability of recording static and dynamic occlusal contact marks using transparent acetate sheet. $J$ Prosthet Dent 2005; 94: 458-461. 